\title{
Understanding the Impact of the Visual Aspect of Coca-Cola China Has on Chinese in the Chinese Market and the Influences on Their Intention Behavior
}

\author{
Yijin Zhao ${ }^{1, \text { a, } \dagger}$, Jingzhi $\mathrm{Xu}^{2, \mathrm{~b}, \dagger}$ \\ ${ }^{1}$ Marketing \& Finance, The University of Sydney, Camperdown, Australia \\ ${ }^{2}$ Marketing, The Ohio State University, Columbus, Ohio, USA \\ ayzha2445@uni,sydney.edu.au, ${ }^{b} x u .3701 @ o s u . e d u$ \\ These authors contributed equally.
}

\begin{abstract}
Coca-Cola won the place for itself in the Chinese market as a global brand. Its successful marketing strategy led to the brand being successful in China worth researching and learning. The purpose of this study is to explore how Chinese purchasing intentions are influenced by the Chinese elements (packaging and color) of Coke. A case study including SWOT analysis will be presented in the following part. It could be concluded that the global brand with Chinese visual elements will stimulate the Chinese purchase intention and then leading to a growing market share.
\end{abstract}

Keywords: Brand Element, Customer purchasing intention, Coca Cola China, Packaging, Color red

\section{INTRODUCTION}

Considering that the competitive beverage market, the taste of soft drinks is not the only standard for consumers. Increasing numbers of customers started to focus on visual aspects of soft drinks to help them make purchase decisions. Jiang and Fan suggested two main development trends of packaging design in the Chinese market: simplified and interactive. For "simplified," the authors point out that due to the faster speed of city life and a massive amount of product news, consumers are aesthetically tired of complicated and irrelevant decorations [1]. Therefore, some practical and straightforward way of delivering information would be preferred by the consumers. In other words, simplified packaging design might become mainstream in the market. For "interactive," instead of one-way information deliverance, companies started to imply various technologies, such as A.R., to create indirect interaction with their prospects [1]. Finally, they concluded that modern soft drink packaging has transformed from an accessory to a meaningful product, which expanded from the original primary protective function to the promotion function and sales function, etc. Thus, the package brings added value to the product and enhances the corporate brand image and popularity nowadays.
There is a growing trend that global brands localize when entering emerging countries. Western designers have been inspired by variable Chinese elements and have been widely applied by global brands [2]. CocaCola has a good understanding of Chinese cultural elements, and appropriately blend the cultural mixing into a brand product design will be effective [2]

To cater to Chinese consumers, Coca-Cola also made adjustments through the development trend of packaging design in the Chinese market. In 2013, CocaCola replaced its logo with some buzzwords on its packaging. In 2014, Coca-Cola printed lyrics on its packaging. Other than these, Coca-Cola also has Spring Festival packaging editions for every Lunar New Year. Multiple reasons are driving Coca-Cola's success and tons of research on the success of Coca-Cola. For example, Sun's research about the influence that Chinese and U.S [3]. Cultures have on Coca-Cola's advertising film and Lili Dang's research about the importance of localized translation packaging products [4]. The purchase decision of Coca-Cola is a routine problem-solving process, which means it's an emotional and low involvement process [5]. Since the decision to purchase soft drinks is mainly driven by emotional factors, color, packaging, and advertising content are tend to be more prominent on Coca-Cola bottles. 
However, researchers seldom focus on the relationship between the color red, packaging, and sales. In this article, we fill the gap with the analysis of CocaCola China. It is meaningful because of the parent brand's leading position in the global scope and its localized marketing strategy with Chinese elements in China, which could be considered a great success. Therefore, this article will focus on Coca-Cola China and analyze the impact of brand elements on Chinese purchase intention.

This article reviews the literature on brand packaging and color based on theories of brand elements, Chinese culture, and consumer purchase intention. The following section is a case study focusing on Coca- Cola. This method is useful in exploring and experimenting with different theoretical perspectives in different environments. Through SWOT analysis, specific identification of Coca Cola China's Strength, Weakness, Opportunity, and Threats provides a better understanding of the Coca Cola actual situation and delivers suggestions for foreign companies intending to invest in China [6]. Then, we conclude with some theoretical implications and suggestions for further research and company application.

\section{LITERATURE REVIEW}

This article will review the impact of package and color on consumer behavior, the relationship between Chinese elements, and cultural pride, which also be imposed significantly on purchase intention.

\subsection{Packaging and its color}

There is a significant number of published studies analyzing the role of packaging and its color. According to Silayoi and Speece, if the product belongs to low involvement, then aesthetic and visual elements of packaging play a necessary role in customer purchase decisions [7]. Alina and Whiley in 2007 showed that packaging color could effectively recall memory and express personality, and $60 \%$ of purchasing decisions are based on color [8]. Cao, in 2009 found that reasonable colors used in packaging have a positive impact on consumers and then affect customer's subjective feelings, which will inspire consumers' purchase intention [9]. Piqueras-Fiszman and Spence provide evidence that the color of the packets exerted a stronger influence on participants' association. Thus, packaging color can be equally important in determining a product's desirability [10]. Pilelienè and Viktorija in 2007 applies a questionnaire to an analysis of the influences of colour temperature on purchase behaviour and found that used in advertisements has a significant impact on consumer purchase intentions [11]. Color has been established as an important variable in the marketing literature and has been shown to affect consumer perceptions of advertising [12]. A study conducted by Luwen et al. in 2007 indicated that intended product-colour purchase decisions are affected by personal colour preferences [13]. In 2013, the color assignment released by Hallock provided information on color preference, in which $7 \%$ of men like red and $9 \%$ of women choose red [14].

Over the past decade, some of the research in brand color pays particular attention to red. According to The Logo Company, red represents excitement, bold and youthful [15]. The color red can be connected with excitement as it is considered an arousing, exciting, and stimulating color [16]. It is generally associated with the characteristics of activity, strength, and stimulation [17]. Consumers tend to choose products color consistent with their emotions, for example, yellow and cheerful[18,19], and the associations are consistent across cultures [20]. In Chinese culture, red also represents good luck and reunion. They apply red in every reunion moment. Color creates emotion and triggers memory [20]. When the Chinese look at CocaCola red and they will recall happiness.

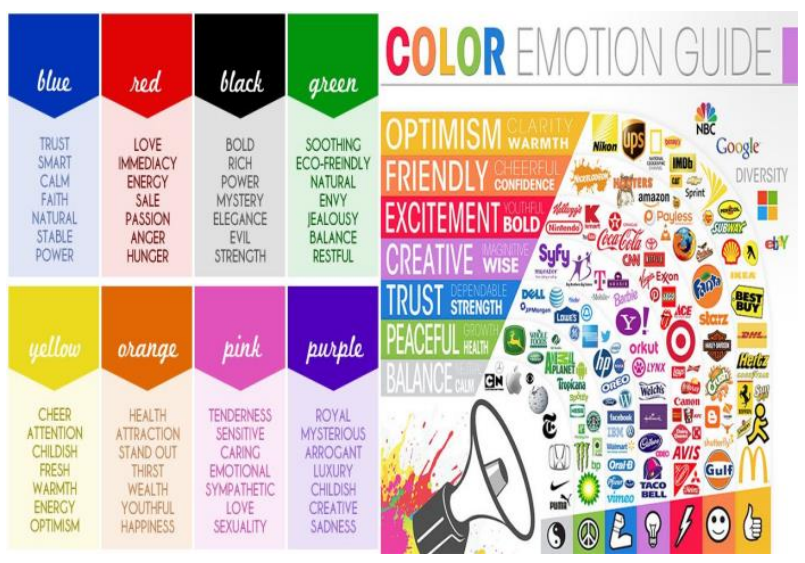

Figure 1. Color Emotion Guide

Source: The Logo Company

\subsection{The impact of Chinese elements on customers purchase decision}

Culture impacts consumer attitudes, the perceived values of products, the characteristics of purchasing behavior, and specific consumption habits [21]. The cultural influences on humans are delivered through behaviour, which means that consumers in different countries and regions often show purchasing behaviour differently [21].

Laroche et al. carried out that the cultural pride of Chinese consumers positively affects purchase intentions toward global brands with Chinese elements [22]. $\mathrm{Wu}$ found that Brands adopting the original Chinese element could positively influence the brandcountry connection and positively influence consumers' purchase intentions [23]. Zhang also indicates that the 
integration strategy has a positive impact on the purchase intention of the host country consumers through the brand cultural identity of the host country consumers [24]. Jiang et al. analyzed the feedback of the luxury brands with Chinese element design in the Chinese market. They reviewed that international brands' design and use of Chinese zodiac elements are mainly aimed at catering to the Asian market, and most of the designs have received positive feedback [25]. Meanwhile, cultural compatibility has a direct positive effect on purchase intention. Dragon icons appearing on Adidas' apparel and Gucci bags; a Panda depicted in Cartier's Watch; Peking Opera facial mask; Pandora's Zodiac Necklace, and Armani Zodiac series makeup are considered as examples of global brands with Chinese elements [21].

However, these studies consider packaging color and Chinese elements separately and do not link them together.

\section{CASE STUDY OF COCA- COLA}

\subsection{History of Coca- Cola}

Dr. John Stith Pemberton created the syrup for Coca-Cola on May 8, 1886 [25]. Dr. Pemberton was a pharmacist from Atlanta, Georgia. In the beginning, Coca-Cola was positioned as a medicine in treatment for indigestion. After adding carbonated water into it, Dr. Pemberton and his partner Frank M. Robinson created this delicious and refreshing soda drink and Coca-Cola brand. Coca-Cola built up a mature global market through the unfolding of history and became dominant in the soft drink market overseas. In 1927, Coca-Cola entered the Chinese market for the first time. However, it experienced a failure due to the name -- "kekekenla." The name didn't arouse people's interest in purchasing the drink. The following year, Coca-Cola made a public announcement and offered $£ 350$ for a new translation for the Chinese company. In the end, Jiang $\mathrm{Yi}$, a Shanghai professor based in the U.K., defeated all his opponents and won the prize. The beverage company has also received the best-translated brand name recognized by the advertising industry-- "Coca-Cola." However, Coca-Cola withdrew from the Chinese market in 1950 due to the evacuation of the U.S. Embassy. On December 19, 1978, the day after China and the United States reannounced the formal establishment of diplomatic relations, Coca-Cola officially announced its return to the Chinese market and signed an agreement with China National Cereals and Oils Import Export Corporation.

\subsection{SWOT Analysis}

A SWOT analysis would be appropriate to use in the following discussion because it can be considered one of the methods measuring consumer perception of a brand. Besides, its two dimensions will clearly represent the strength, weaknesses, opportunities, and threats based on the visual aspects of Coca-Cola China.

\subsubsection{The strength of Coca-Cola}

Coca-Cola was rated the most valuable soft drink brand worldwide in 2020, and it occupies $48 \%$ of the global market [26]. As a leading position brand, CocaCola returned to China in 1978 and won three titles of market share, best brand, and popularity among similar products, which was announced in the "1999 China National Urban Consumer Survey" [27]. Besides its mature system and experience, another driver behind its success in China might be the brand iconic red. Through the unfolding of Chinese history, red has always symbolized luck, happiness, and niceness. Thus it is easy to understand that products with red might appear in Chinese families frequently, such as reunion or family party. According to the study done by Laroche et al., the researchers point out the positive relationship between Chinese consumers and global brands with Chinese elements [28]. The theme color red of CocaCola can easily connect Chinese consumers with the place where they grow up. Therefore, the consistency of the visual aspect of the product provides Coca-Cola with natural strength in the Chinese market.

Coca-Cola also localized with a variety of packaging strategies. In 2000, Coca-Cola China launched its new advertising called "Dragon Dance ", because the dragon is a traditional Chinese mascot, and the dragon dance is a celebration of traditional Chinese festivals. These ads were well received by the Chinese [28]. Moreover, Coca-Cola applied "Coke my name" into the Chinese market and changed its specific name to internet hot words, which show more personality. This move was also popular among Chinese consumers, and they bought their own personal Coca-Cola and shared it with Moments [29].

\subsubsection{Weakness of Coca-Cola}

The weakness relies on the conflict between traditional Chinese views towards health and unhealthy ingredients of Coca-Cola. Coca-Cola is known as one of the most popular but unhealthy soft drink brands, bringing happiness with a sweet flavor. According to the research done by Vartanian et al. on the effects of soft drink consumption on human nutrition and health, the finding shows a negative relationship between health and soft drink consumption [30]. The research uncovered the fact that the energy offered by soft drinks linked to several critical health concerns, such as diabetes. Meanwhile, Chinese customers consider health more significant than other races, making decisions more cautiously and choosing healthier and fewer 
sugary beverages. The reason behind it is that traditional Chinese medicine plays an essential role in their culture. They value and attach importance to health maintenance. However, although the company introduced diet Coke, Coke Zero, and other fewer sugar alternatives to the market, the brand image is difficult to change.

\subsubsection{The opportunity of Coca-Cola}

The red colour of Coca-Cola also could be applied to multiple conditions and then create opportunities for Coca-Cola. Firstly, Coca-Cola sponsored tons of sports activities Coca-Cola in China to actively promote the development of China's sports industry [35]. For example, Coca-Cola spares no effort to promote Olympic culture in China, share Olympic passion and vitality with ordinary Chinese, and use the Olympic platform to show China to the world. They took corporate social responsibility. Thus Coca-Cola China's Coca-Cola 520 project won the third "CSR China Education Award" and CSR CHINA Model Award in 2018 On September 20, 2018 [32].

Meanwhile, during the pandemic, Coca-Cola had donated epidemic preventions and supplies to over 12 provinces. Overall, it has donated more than three hundred thousand water bottles for doctors and nurses in hospitals all over China. In April 2020, Coca-Cola also released "Loving Path \& Expressing Love Toward Wuhan" unique bottle design [31]. There are four editions, and each edition shows an element of the City. The red color is meaningful during this period. It brings hope, hove, and faithfulness to the whole country. As a result, both the donation and the unique design built emotional connections between Coca-Cola and Chinese consumers, resulting in increased revenue for the quarter. [31].

\subsubsection{The threats of Coca-Cola}

The COVID-19 pandemic might generate new threats to Coca-Cola. When considering the beverage market during an epidemic, local competitive brands will pose a threat to Coca-Cola. Firstly, the local policies are intended to protect Chinese brands rather than global brands, which might help local brands develop and increase their market share during such a period. Besides, due to the epidemic outbreak in Wuhan at the beginning of 2020, the Chinese government locked down Wuhan city. At the same time, people in other cities are encouraged to study and work from home. The limitations in daily life due to the pandemic also raise lots of health concerns for people, such as the increase in weight resulting from limited working out conditions. Because of the appearance of these health concerns and the fact of the COVID-19 outbreak, teenagers started to pay more attention to health maintenance as well. Thus, they will purchase healthier products alternatives from local companies, such as Wahaha and Lulu, which might lead to a declined revenue [32].

\subsection{Result}

The red color of Coke packaging will provide strength for the brand as Chinese consumers consider red as a representative of good luck, happiness, and energy. Meanwhile, the brand takes their corporate social responsibility during tons of Chinese activity and a pandemic, their brand image. However, the weakness relies on the conflict between Chinese traditional medicine culture and Coke's negative brand image. Consumers consider coke as an unhealthy soft drink but Chinese value health preservation. As a result, they tend to have healthier and fewer sugar alternatives. The threats are generated from the local competitive brands because they are likely to receive protection from the local government. Both weakness and threats will lead to a declined revenue of Coke.

\section{DISCUSSION}

Through the SWOT analysis, the research uncovered the influence on the Chinese market by using elements related to Chinese culture. Because of the cultural background of Chinese consumers, it is easier to build up an emotional connection with them through marketing decisions with Chinese cultural elements, such as the "Expression Love Toward Wuhan" edition bottles. Once the emotional connection is built, it will also result in revenue and market share. In other words, this is also why Coca-Cola is in the dominant position in the soft drink market in China. This research also reinforced the result from the research done by (Laroche et al.). Admittedly, since the current research focuses on a case study of Coca-Cola, it will limit case studies in other areas.

\section{CONCLUSION}

We have presented a case study to analyze the impact of packaging and color on Chinese consumers' purchase decisions through a case study of Coca-Cola China. Our finding is that the global brand with Chinese visual elements will stimulate the Chinese customer purchase intention and then help the brand win Chinese market share more easily. The experience of Coca Cola China provides other global brands with reference and lessons, especially those brands which provide low involvement products. They might need to attract customers with localized brand elements and make movements, such as new strategies related to color and packaging. Meanwhile, the case analysis also provides suggestions to foreign companies which intend to invest in China on how it should be done. However, future 
research on the case study of other brands might extend the relationship between customers' purchase intention and brand elements.

\section{REFERENCES}

[1] Jiang, Tian-yu, and Li-yuan Fan. "Current Situation and Development Trend of Packaging Design for Beverages in China." Packaging Engineering, 2019. Chinese Academic Journal Electronic Publishing House, doi:10.19554/j.cnki.10013563.2019.14.013.

[2] He, Jiaxun, and Cheng Lu Wang. "How Global Brands Incorporating Local Cultural Elements Increase Consumer Purchase Likelihood." International Marketing Review, vol. 34, no. 4, 2017, pp. 463-79. Crossref, doi:10.1108/imr-082014-0272.

[3] Sun Aijun. The influence of Chinese and American cultures on Coca Cola's video advertisement. Time Report.01(2021):6465.doi:CNKI:SUN:SDBB.0.2021-01-030.

[4] Dang Lili. Localized Translation of Sales Packaging: A Case Study of Coca-Cola Sales Packaging Translation. China Packaging 39.03(2019):35-44. doi:CNKI:SUN: zbzz.0.2019-03-021.

[5] Gourville, John T., and Michael I. Norton. Marketing Reading: Consumer Behavior and the Buying Process. Harvard Business Publishing, 2014.

[6] Shen, Minglei, and Yao Tianxiang. "The effects of Chinese Culture onInternal Management and Marketing Strategie: Case Study on Coca-Cola (China) and NEC (China)." (2011).

[7] Silayoi, Pinya, and Mark Speece. "Packaging and purchase decisions: An exploratory study on the impact of involvement level and time pressure." British food journal (2004).

[8] Wheeler, Alina. Designing brand identity: an essential guide for the whole branding team. John Wiley \& Sons, 2017.

[9] Cao Yingzhao. Research on the influence of packaging color choice on consumers' purchase intention. Modern Economic Information. 21(2019):117-118. doi:CNKI:SUN:XDJZ.0.201921-097.

[10] Piqueras-Fiszman, Betina, and Charles Spence. "Crossmodal correspondences in product packaging. Assessing color-flavor correspondences for potato chips (crisps)." Appetite 57.3 (2011): 753-757.
[11] Pilelienè, Lina, and Viktorija Grigaliūnaitè "Colour temperature in advertising and its impact on consumer purchase intentions." Oeconomia Copernicana 8.4 (2017): 657-669.

[12] Gorn, Gerald J., et al. "Effects of color as an executional cue in advertising: They're in the shade." Management science 43.10 (1997): 13871400 .

[13] $\mathrm{Yu}$, Luwen, et al. "The role of individual colour preferences in consumer purchase decisions." Color Research \& Application 43.2 (2018): 258267.

[14] Hallock, Joe. "Colour Assignment." Joe Hallock, 2003, www.joehallock.com/?page_id=1281.

[15] Admin. "The Psychology Of Color In Logo Design." The Logo Company, 27 Dec. 2020, thelogocompany.net/psychology-of-color-in-logodesign.

[16] Bellizzi, Joseph A., Ayn E. Crowley, and Ronald W. Hasty. "The effects of color in store design." Journal of retailing (1983).

[17] Fraser, Tom, and Adam Banks. Designer's color manual: The complete guide to color theory and application. Chronicle Books, 2004.

[18] Collier, Geoffrey L. "Affective Synesthesia: Extracting Emotion Space from Simple Perceptual Stimuli." Motivation and Emotion, vol. 20, no. 1, 1996, pp. 1-32. Crossref, doi:10.1007/bf02251005.

[19] Levy, Bernard I. "Research into the psychological meaning of color." American Journal of Art Therapy (1984).

[20] D'ANDRADE, Roy, and Michael Egan. "The colors of emotion 1." American ethnologist 1.1 (1974): 49-63.

[21] Wild, John, and Kenneth Wild. International Business: The Challenges of Globalization (5th Edition) \& MyIBLab with Pearson EText (6th Edition). 5th ed., Prentice Hall, 2009.

[22] Laroche, Michel, et al. "Understanding Chinese Consumers' and Chinese Immigrants' Purchase Intentions toward Global Brands with Chinese Elements." Journal of Product \& Brand Management, vol. ahead-of, no. ahead-of-print, 2020. Crossref, doi:10.1108/jpbm-09-2019-2578.

[23] WuJingxian. Research on the strategy types of brand integrating Chinese elements and its influence on consumers' purchase intention. 2020. East China Normal University. MA thesis.

[24] Zhang Xiaoqi. The influence of luxury brand crosscultural integration strategy on consumers 
purchase intention in host country. 2020. Jiangxi Normal University. MA thesis.

[25] Jiang Haixiao, et al. Cross-cultural research on Chinese elements in international luxury brands, take the zodiac exclusive products of Armani, Gucci and longchamp as an example. PR Magazine. 12(2019):238-239. doi:10.16645/j.cnki.cn11-5281/c.2019.12.198.

[26] History of Cocacola. Journey. 2015. www.cocacola.com.cn/history.

[27] Wikipedia. "Coca-Cola." Wikipedia, the free encyclopedia, 22 Apr., 2021, zh.wikipedia.org/wiki/\%E5\%8F\% AF\%E5\%8F\%A $3 \% \mathrm{E} 5 \% 8 \mathrm{~F} \% \mathrm{AF} \% \mathrm{E} 4 \% \mathrm{~B} 9 \% 90$.

[28] Yong L. \& Pong Z., Research on the brand marketing strategy of Coca Cola in China." East China economic management. .06(2007):99-101. doi:10.19629/j.cnki.34-1014/f.2007.06.023.
[29] Nan S. \& Nian L., Collectivism or Individualism? - Contemporary Chinese cultural values as seen from Coca Cola's Chinese localized advertisements.07(2019):57-61.DOI: CNKI:SUN:XWZS.0.2019-07-016.

[30] Vartanian, Lenny R., et al. "Effects of Soft Drink Consumption on Nutrition and Health: A Systematic Review and Meta-Analysis." American Journal of Public Health, vol. 97, no. 4, 2007, pp. 667-75. Crossref, doi:10.2105/ajph.2005.083782.

[31] Being and caring with society Journey, 2021, www.coca-cola.com.cn/WeCare/sqfz.

[32] Coca-Cola's Q1 2021 revenue up 5\% year over year, China performance ahead of 2019 level. Journey, 21 Apr. 2021, www.cocacola.com.cn/press-centre/pressreleases/kkklgs2021nq1ystbzz. 